\title{
CAMBIOS EN LA DINÁMICA DE LA ECONOMÍA CAMPESINA A PARTIR DE LA ADOPCIÓN DE LA PALMA DE ACEITE EN EL Soconusco, Chiapas
}

\author{
Changes in the Dynamics of the Peasant Economy \\ since the Adoption of Oil Palm in Soconusco, Chiapas
}

\author{
Eliezer Fernando Pérez Pérez* \\ Daniel Villafuerte Solís*** \\ DOI: https://doi.org/10.31644/ED.V8.N1.2021.A04
}

\begin{abstract}
Resumen: En los últimos años hemos asistido a un proceso de cambios en las economías de América Latina que se expresan en lo que se ha llamado "reprimarización" y "financiarización" de la economía. Un fenómeno que altera la dinámica de la producción local y las condiciones de vida de la población campesina. Esto se puede observar en el Soconusco, Chiapas, donde el cultivo de la palma de aceite se ha convertido en el sustento económico principal de miles de familias campesinas. El artículo analiza los cambios generados en la dinámica de la economía campesina a partir de la adopción del cultivo de palma desde la década de 1990, relacionados con el uso de suelo y la estacionalidad de la agricultura. Se destaca que, si bien para los campesinos la palma es más rentable que otros cultivos, incluso que la ganadería, su dinámica de producción conlleva cambios sustanciales en su relación con el mercado y con la naturaleza. El análisis parte de la teoría campesina en el contexto de globalización neoliberal, y se basa en el trabajo de campo realizado en los municipios de Huixtla, Villa Comaltitlán y Mapastepec, entre junio de 2017 y enero de 2020.
\end{abstract}

Palabras clave: globalización neoliberal, mercado, agroindustria, palma aceitera, lógica campesina.

Abstract: In recent years we have observed a process of changes in Latin American economies that are expressed in what has been called the "reprimarization" and "financialization" of the economy. This phenomenon has changed the dynamics of local production and the living conditions of

\footnotetext{
* Mtro. en Ciencias en Desarrollo Rural Regional, Doctorante en Ciencias en Desarrollo Rural Regional, Universidad Autónoma Chapingo, México. ORCiD: https://orcid.org/0000-0003-0411-290X Correo-e: pepe cielo@hotmail.com.

** Doctor en Ciencias Sociales, Profesor-investigador titular de tiempo completo del Centro de Estudios Superiores de México y Centroamérica de la Universidad de Ciencias y Artes de Chiapas, México. ORCiD: https://orcid. org/0000-0002-5866-4534 Correo-e: gasoda 2000@yahoo.com.mx.
}

Fecha de recepción: 19/06/2020. Fecha de aceptación: 16/11/2020. Fecha de publicación: 30/01/2021.

\section{(cc) BY-NC-ND}

EntreDiversidades. Revista de Ciencias Sociales y Humanidades, vol. 8, núm. 1 (16), enero-junio 2021. Páginas: 92 - 118 ISSN-e: 2007-7610. https://doi.org/10.31644/ED.V8.N1.2021.A04 
the peasant population. These processes can be observed in Soconusco, Chiapas, where the cultivation of oil palm has become the main economic livelihood of thousands of peasants families. This article analyzes the changes that it has generated in the dynamics of the peasant economy since its adoption in the 1990s, related to land use and the seasonality of agriculture. It is highlighted that, although for the peasants, palm is more profitable than other crops, including livestock, its production dynamics entails substantial changes in its relationship with the market and the nature. The analysis draws from peasant theory in the context of neoliberal globalization, and is based on field work carried out in the municipalities of Huixtla, Villa Comaltitlán, and Mapastepec, between June 2017 and January 2020.

Keywords: neoliberal globalization, agroindustry, oil palm, market, peasant logic.

\section{Introducción}

La expansión de la palma de aceite (elaeis guineensis Jacq.) en México es producto del proceso de globalización neoliberal, y corresponde a un momento determinado de desarrollo de la economía mexicana, inmersa en la gravitación de la expansión y reproducción del capital global (Holloway, 1992). Como fenómeno económico la globalización neoliberal en América Latina arrancó con el golpe de Estado en Chile en 1973, y se consolidó durante la década de 1980 en el contexto de la crisis de la deuda externa, auspiciada por el Fondo Monetario Internacional (FMI) y el Banco Mundial (BM). Esto, como salida a la crisis económica y política provocada por la decadencia de las políticas keynesianas y del modelo de producción fordista. En este proceso, tanto el FMI como el BM implementaron el programa de ajuste estructural en los países subdesarrollados, con el propósito de incrementar la producción, ampliar el comercio y saldar la deuda. Para ello, colocaron al capital privado como motor del crecimiento económico, redujeron las funciones del Estado y abrieron la economía a la dinámica del mercado mundial (Guillén, 2000; Ortiz, 2001; Wallerstein, 2005).

En México, el ajuste estructural neoliberal se empezó a implementar desde 1982 y se concretizó con su adhesión al GATT (Acuerdo General de Aranceles y Comercio, por sus siglas en inglés) en 1986, con el cierre y privatización de empresas paraestatales, con la reforma al artículo 27 constitucional en 1992 y con el inicio del Tratado de Libre Comercio con Estados Unidos y Canadá en 1994 (Acosta, 2006). En el campo, estas políticas estuvieron orientadas a la modificación de la tenencia de la tierra, a la reconversión productiva y a la reorganización de la comercialización de los productos agrícolas, bajo el discurso de la modernización del campo mexicano (Peńa y Romero, 1995). En este sentido, el Estado redujo los incentivos económicos destinados a las actividades agrícolas tradicionales como el cultivo de maíz, frijol, café, plátano, mango, entre otros, y los aumentó para la producción de hortalizas, frutales y cultivos industriales como la soya y la palma de aceite (Rubio y Moguel, 2018).

Esto llevó a una parte de los productores que cumplían con las condiciones necesarias para estos tipos de cultivo a iniciar procesos de reconversión productiva, lo que desembocó en el fortalecimiento de la industria agroexportadora (nacional y extranjera) en el país y de las grandes

EntreDiversidades. Revista de Ciencias Sociales y Humanidades, vol. 8, núm. 1 (16), enero-junio 2021. Páginas: 92 - 118 ISSN-e: 2007-7610. https://doi.org/10.31644/ED.V8.N1.2021.A04 
empresas transnacionales que dominan el mercado agroalimentario mundial (Rubio, 2003; McMichael, 2015). De esta manera, la población campesina que adoptó el cultivo de la palma de aceite entró a una nueva dinámica de acumulación del capital, donde convergen los procesos de reprimarización y financiarización de la economía (Ramírez, 2011).

En este contexto, el cultivo de la palma de aceite en México pasó de una superficie sembrada de 568 hectáreas en 1983, ubicadas en Chiapas, a 101753 hectáreas en 2018, de las cuales, 45\% se localizaba en Chiapas, 27\% en Campeche, $21 \%$ en Tabasco y 7\% en Veracruz (SIAP, 2019). Es decir, en 35 ańos las plantaciones de palma se expandieron exponencialmente, lo que muestra la orientación de la política agrícola nacional en el proceso de globalización neoliberal. Lo relevante de este proceso es que Chiapas, al igual que con otros cultivos como el café, se ha colocado al frente de la producción de palma de aceite, reivindicando así su importancia en el desarrollo de la agricultura nacional. También se destaca que, de las 45426 hectáreas sembradas en el territorio estatal hasta 2018, 27500 hectáreas se ubicaron en la región Soconusco, equivalente al 60\% de la superficie estatal y al $27 \%$ de la superficie nacional; el resto corresponde a las regiones Selva, Norte y Costa de Chiapas (SIAP, 2019).

En el Soconusco, ${ }^{1}$ el cultivo de la palma de aceite tiene sus antecedentes en la década de 1950 (Castellanos, 2018). Sin embargo, su adopción y expansión por parte de las familias campesinas comenzó en la década de 1990, en el marco del proceso de reconversión productiva emprendida por los gobiernos federal y estatal. De hecho, se estima que en la región existen alrededor de 4780 palmicultores, entre campesinos y propietarios privados, quienes comercializan su producto con empresas de capital privado o empresas campesinas, algunos de forma organizada, la mayoría como productores "libres" (Trejo, Valdiviezo y Fletes, 2018). Es necesario mencionar que, si bien el tamaño promedio de la superficie palmícola es de seis hectáreas por productor, el tamaño de la superficie familiar es muy variable, dependiendo del tipo de propiedad.

El propósito de este artículo es analizar los cambios generados en la dinámica de la economía campesina a partir de la adopción del cultivo de palma desde la década de 1990, relacionados con el uso de suelo y la estacionalidad de la agricultura. Esto considerando que muchos campesinos sustituyeron sus cultivos de maíz, frijol o mango, incluso la ganadería, por la palma, lo que implicó cambios sustanciales en su relación con el mercado y con la naturaleza.

El estudio se basa en información de campo obtenida con productores de palma de algunos ejidos de los municipios de Huixtla, Villa Comaltitlán y Mapastepec, entre junio de 2017 y enero de 2020. En este periodo se realizaron estancias y recorridos de campo con algunos productores, pláticas con jornaleros y 22 entrevistas abiertas a productores. Además, se consultaron fuentes bibliográficas y estadísticas oficiales para poner en contexto el avance de la superficie palmícola en la región de estudio. El análisis parte de una perspectiva que incorpora la teoría campesina en el contexto de la llamada reprimarización y financiarización de la economía, bajo el enfoque histórico-estructural, el cual permite identificar procesos de cambio, continuidades y rupturas.

\footnotetext{
${ }^{1}$ La región está integrada por 16 municipios: Tapachula, Frontera Hidalgo, Suchiate, Metapa, Tuxtla Chico, Unión Juárez, Mazatán, Cacahoatán, Huehuetán, Tuzantán, Huixtla, Escuintla, Villa Comaltitlán, Acacoyagua, Acapetahua y Mapastepec. Aunque la nueva regionalización decretada en 2011 ubica al municipio de Mapastepec en la Región IX Istmo-costa, aquí se retoma la regionalización anterior a dicho ańo, donde este corresponde a Soconusco.
}

EntreDiversidades. Revista de Ciencias Sociales y Humanidades, vol. 8, núm. 1 (16), enero-junio 2021. Páginas: 92 - 118 ISSN-e: 2007-7610. https://doi.org/10.31644/ED.V8.N1.2021.A04 
El documento está integrado por cinco apartados: el primero constituye el cuerpo analítico del artículo, que permite entender el proceso de cambio en el patrón productivo de los campesinos; el segundo es el contexto de la producción de palma de aceite en Chiapas; el tercero se refiere a la estructura agraria y productiva de la región, que sitúa a los municipios más importantes en la producción de palma; el cuarto trata de la importancia económica que tiene el cultivo de palma para los campesinos; y el quinto apartado analiza los cambios en la economía campesina a partir de un ejido del municipio de Mapastepec, que ilustra las diferentes circunstancias que propician la adopción de diferentes estrategias de sobrevivencia, hasta llegar al cultivo de la palma aceitera.

\section{Lógicas campesinas en el contexto de desarrollo del capital}

Históricamente, el Soconusco ha sido una de las regiones más dinámicas en la producción agrícola, principalmente en la agricultura mercantil y de exportación, algo que lo distingue de otros territorios de Chiapas. Aunque su importancia económica deviene desde tiempos prehispánicos con el cultivo del cacao, la agricultura mercantil a la que hacemos referencia se empezó a desarrollar con el asentamiento de las fincas cafetaleras desde finales del siglo XIX (Tovar, 2006; Fenner, 2010). Este proceso trajo consigo la inversión de capital privado (nacional y extranjero) y una nueva dinámica en la producción agrícola de la región. Esto, en sintonía con los procesos productivos y comerciales implementados en México y en América Latina, enmarcados en el modelo de desarrollo "primario exportador" (Pareyón, 2015).

El proceso de la Revolución mexicana (1910-1921) y la Reforma agraria emprendida por el gobierno de Lázaro Cárdenas (1934-1940) permitió que muchos campesinos, trabajadores asalariados y peones acasillados de las fincas y ranchos gestionaran tierras por la vía de la dotación ejidal, lo que llevó a un cambio en la estructura agraria de la región (Reyes, 1992; París, 2006). Una parte de los nuevos ejidatarios empezó su vida de campesino cultivando maíz, frijol, calabaza, chile, entre otros, dependiendo de su ubicación geográfica y condiciones naturales. Otra, aparte de sus esfuerzos por cultivar granos básicos, optó por sembrar uno o dos cultivos para el mercado, entre los que se destaca el café, cacao, plátano, ajonjolí, arroz, o criar algún tipo de ganado. Sin embargo, conforme fue creciendo la población al interior de los ejidos, y con ello sus necesidades de consumo, casi todos terminaron concurriendo en el mercado (Pérez, 2011).

En este tipo de economía de subsistencia "la composición de la unidad económica familiar define ante todo los límites máximo y mínimo del volumen de su actividad económica" (Chayanov, 1974: 47). Esto significa que cuando la unidad agrícola (por razones del clima, estación, plagas, etc.) no logra proveer los recursos necesarios para la subsistencia, la fuerza de trabajo familiar se orienta a potencializar otras actividades como las artesanales y comerciales, de modo que "la medida de la auto-explotación depende en mayor grado del peso que ejercen sobre el trabajador las necesidades de consumo de la familia" (Chayanov: 1974: 81). Sin embargo, conforme los campesinos van entrando a la dinámica del mercado "sustituyen, total o casi totalmente, la producción de alimentos para el propio consumo por la compra de éstos" (Calva, 1988: 363), pues, en el mercado, el dinero "es la forma o manifestación necesaria de la medida inmanente

EntreDiversidades. Revista de Ciencias Sociales y Humanidades, vol. 8, núm. 1 (16), enero-junio 2021. Páginas: 92 - 118 ISSN-e: 2007-7610. https://doi.org/10.31644/ED.V8.N1.2021.A04 
de valor de las mercancías" (Marx, 1999 [1867]: 72). Es el punto de arranque del capital, y se presenta como el elemento que cubre los distintos ámbitos del consumo y de la producción.

Hasta la década de 1950 la estructura productiva del Soconusco "se caracterizó por el predominio de las plantaciones de café y plátano, las cuales concentraron todos los recursos y centralizaron el proceso de acumulación de capital" (Villafuerte, 1992: 12). Sin embargo, con la introducción del cultivo del algodón, la soya, el tabaco y la caña de azúcar comenzó una serie de cambios en el sector agrícola, reflejados en la intensificación del uso del suelo, el empleo de nuevas tecnologías y la utilización masiva de agroquímicos. Recordemos que en esta etapa, en varios enclaves agrícolas del país, bajo el argumento de incrementar la productividad de los nuevos cultivos y los tradicionales (maíz, café, plátano) se implementaron una serie de procesos técnicos y científicos enmarcados en la llamada "revolución verde" (Pichardo, 2006). Este fenómeno propició una nueva dinámica en la plataforma productiva de la región, en concordancia con el modelo de industrialización por sustitución de importaciones, donde "los obreros se integraban como fuerza de trabajo y como consumidores, mientras que los campesinos se integraban como productores de alimentos baratos" (Rubio, 2003, 47).

A este proceso de integración de la población campesina al desarrollo de la economía nacional, Rubio (2003) lo nombró como "la subordinación incluyente del capital”. Esto debido a que los campesinos encontraron cierto apoyo en las instituciones gubernamentales - como créditos y obras de infraestructura- que favorecieron al desarrollo de la agricultura capitalista. En este sentido, Schejtman (1980) argumenta que los campesinos tienden a valorar sus opciones de producción, echan a andar sus ideas y planean sus actividades económicas, puesto que la lógica campesina va más allá de sus necesidades de consumo y se basa, sustancialmente, en "asegurar, ciclo a ciclo, la reproducción de sus condiciones de vida y de trabajo o, si se prefiere, la reproducción de los productores y de la propia unidad de producción” (Schejtman, 1980: 123).

Por eso, en una economía de mercado capitalista se deben tomar en cuenta "las relaciones sociales de producción locales, las formas organizativas del mercado local y el carácter de la penetración del capitalismo comercial y financiero" (Chayanov, 1974: 73) en las unidades campesinas. Pues estas, en su afán de incrementar sus ingresos monetarios, tienden a especializarse "en un solo producto (o en un par de productos) para el mercado, y con frecuencia creciente ni siquiera en un producto terminado, listo para el consumo, sino en una materia prima" (Calva, 1988: 365). Ante ello, uno de los problemas principales al que los campesinos se enfrentan es que los precios de su producto son establecidos por el mercado, lo que de entrada significa una relación de intercambio desigual y de dependencia económica (Bartra, 1972). Situación que muchas veces, sobre todo en tiempos de crisis, los ha llevado a buscar trabajo asalariado temporal dentro o fuera de su comunidad.

Para la década de los setenta y ochenta, el Estado, a través de empresas paraestatales como el Instituto Mexicano del Café (INMECAFÉ) y Tabacos Mexicanos (Tabamex), brindó asesoría técnica, precios de garantía y créditos (en efectivo y en especie) con el propósito de impulsar la producción campesina. Estas políticas se implementaron en un momento en que la producción de café todavía representaba uno de los pilares de la economía de la región (Renard, 1993). Sin embargo, simultáneamente otros cultivos se expandieron en tierras campesinas, entre los que se

EntreDiversidades. Revista de Ciencias Sociales y Humanidades, vol. 8, núm. 1 (16), enero-junio 2021. Páginas: 92 - 118 ISSN-e: 2007-7610. https://doi.org/10.31644/ED.V8.N1.2021.A04 
destaca la cańa de azúcar y el mango, que no solo permitieron un nuevo giro en el desarrollo agrícola del Soconusco, sino también una articulación mayor de la producción campesina con el capital privado (Villafuerte, 1992).

De esta manera, los campesinos del Soconusco se han ido adhiriendo a nuevas prácticas de producción, sobre todo el sector que se ubica en la planicie costera, cuyas condiciones climáticas y de suelo permiten cambios en el patrón de cultivo, orillándolos a ser más proclives a la dinámica del mercado. En esta dinámica los precios representan un termómetro que varía drásticamente entre la "prosperidad" o la ruina, tal como quedó demostrado con la crisis de los precios internacionales del café de 1989 y 2001, que obligaron a miles de campesinos de la región a abandonar sus parcelas y migrar en busca de trabajo asalariado a los estados del centro y norte del país, así como a Estados Unidos (Villafuerte y García, 2014).

En esta tesitura, desde la década de 1990 muchos campesinos y pequeños productores entraron al proceso de "reconversión productiva" liderada por la palma de aceite, cuyos incentivos principales fueron el apoyo gubernamental —materializado en suministro de plantas, fertilizantes químicos e incentivos monetarios-y un precio más competitivo que el maíz, el frijol, el mango u otros cultivos de la región (Santacruz y Palacio, 2018). Así, el desarrollo de la producción de palma de aceite favoreció el acercamiento de las relaciones entre campesinos y empresas agroindustriales (nacionales y multinacionales) vinculadas al mercado agroalimentario mundial, las cuales operan bajo la lógica que establece como principio la obtención de ganancias (Marx, 1999 [1867]). Esta lógica hace que las relaciones sociales de producción se introyecten en la población campesina a través de la producción de mercancías y el aumento de la productividad por medio del uso de fertilizantes químicos. Es por ello que "el desarrollo de una sociedad de mercado ha representado, en general, el determinante más significativo de los cambios estructurales de las comunidades rurales" (Shanin, 1983:61), que en este caso es impulsado con el cultivo de la palma.

Lo relevante de este proceso es que la expansión del cultivo de palma aceitera se enmarca en el modelo económico neoliberal, cuya estrategia "se orientó a transferir a los agentes privados y al mercado, gradual pero sostenidamente, las funciones económicas anteriormente asignadas al Estado" (Calva, 2019, 582-583). En el campo, las consecuencias de estas políticas se vieron reflejadas mayormente en el cierre y privatización de empresas paraestatales que apoyaban y financiaban a los pequeños productores. Además, la reforma al artículo 27 constitucional abrió el camino para la privatización de las tierras ejidales y la puesta en marcha del Tratado de Libre Comercio con Estados Unidos y Canadá propició una competencia desigual para los campesinos mexicanos, permitiendo la importación masiva de granos básicos (Acosta, 2006).

En esta etapa, la población campesina quedó inmersa en una nueva dinámica de acumulación de capital, comandada por el capital agroindustrial, lo que trajo consigo la profundización de "la exclusión productiva de los campesinos, la dependencia alimentaria, la migración y la pobreza rural” (Rubio, 2019: 17). El Estado marginó a los campesinos y los convirtió en objeto de programas sociales, negando su importancia económica y productiva, pues para la ideología neoliberal, la economía campesina debe desaparecer porque no cumple con los principios 
fundamentales del mercado: eficiencia y competitividad. Es por ello que Rubio (2003) nombró a este proceso "la subordinación excluyente del capital", cuya característica principal es el dominio del capital financiero sobre el productivo.

\section{La expansión de la palma de aceite en Chiapas en el proceso de globalización neoliberal}

Uno de los argumentos para la liberalización de los mercados en el proceso de globalización neoliberal fue el aprovechamiento de las ventajas comparativas de cada país. Para los países subdesarrollados de América Latina, incluyendo a México, correspondió la producción y exportación de productos primarios agropecuarios, mineros y petrolíferos hacia los países desarrollados, principalmente a Estados Unidos. Por eso se dice que en este proceso "la tierra y la explotación de recursos naturales en general se convirtieron en muy atractivas para el capital global" (Kay, 2016: 11), representado por la gran industria y las empresas transnacionales agroexportadoras. Ante ello, los cultivos tradicionales como maíz, café, banana, cacao, entre otros, redujeron su rentabilidad en el mercado de exportación frente a los nuevos productos derivados de la horticultura, la floricultura y la fruticultura, orillando a los productores "a cambiar su producción por el ahora rentable mercado de exportación” (Kay, 2016: 7).

Este tipo de actividades agrícolas tomaron mayor importancia con la crisis financiera global de 2008, que develó las crisis alimentaria y energética mundial subyacentes al modelo neoliberal y al sistema capitalista (Rubio, 2013). En este contexto de crisis, la Organización de las Naciones Unidas para la Alimentación y la Agricultura (FAO, por sus siglas en inglés) junto a otras instituciones de carácter regional y los gobiernos nacionales incentivaron, por un lado, la producción de hortalizas y frutas en la pequeña agricultura familiar y campesina y, por otro, "la producción de agrocombustibles provenientes de la soya, la palma africana, el maíz y la cańa de azúcar" (Rubio, 2018: 28).

Este nuevo giro hacia el sector primario y su peso significativo en la balanza comercial es lo que algunos han nombrado como la reprimarización de las economías subdesarrolladas (Teubal y Palmisano, 2015) o el consenso de las commodities (Svampa, 2017), el cual llegó acompañado de un modelo "neoextractivista", cuyo rasgo fundamental es la extracción de bienes primarios con la participación del Estado (Gudynas, 2009; Gudynas, 2012; Lander, 2014). Además, con la globalización neoliberal prácticamente todas las esferas y ramas de la economía son sometidas al llamado proceso de financiarización, donde los productos se bursatilizan y pasan a formar parte del mundo especulativo. La palma aceitera no es la excepción, se trata de un proyecto agroindustrial global articulado a la especulación de los mercados financieros, donde los campesinos y productores del mundo se ven arrastrados a esa lógica (Ramírez, 2011; Echánove, 2017).

De esta manera, en la expansión de la palma confluyen los intereses del capital privado con los intereses del Estado, ambos enfocados hacia la reestructuración productiva con un cultivo más rentable para el mercado (Trejo, Valdiviezo y Fletes, 2018). Esta rentabilidad se expresa en un incremento progresivo de la demanda del aceite de palma en la industria agroalimentaria y energética nacional y mundial, así como en el precio de la materia prima (Santacruz y Palacio,

EntreDiversidades. Revista de Ciencias Sociales y Humanidades, vol. 8, núm. 1 (16), enero-junio 2021. Páginas: 92 - 118 ISSN-e: 2007-7610. https://doi.org/10.31644/ED.V8.N1.2021.A04 
2018). Así, instituciones como la Secretaría de Agricultura, Ganadería, Desarrollo Rural, Pesca y Alimentación (SAGARPA) y Fideicomisos Instituidos en Relación a la Agricultura (FIRA) implementaron varios programas de reconversión productiva que llevaron al boom de la palma aceitera, aunque en algunos casos, estos programas llegaron a la población campesina mediante prácticas políticas corporativas (Castellanos, 2018).

A ello se agrega el impulso del Estado a este cultivo a través de mecanismos regionales como el Proyecto Mesoamérica (antes Plan Puebla-Panamá). En este marco, en 2008 se creó el Programa Mesoamericano de Biocombustibles y la Red Mesoamericana de Investigación y Desarrollo en Biocombustibles, con el propósito de fomentar la investigación y la transferencia de tecnología, destacando su vínculo técnico y financiero con el Banco Interamericano de Desarrollo (Proyecto Mesoamérica, 2013). Esto confirma que el proyecto agroindustrial de la palma aceitera es global, y no deja dudas de que los campesinos están frente a una nueva realidad, que aparece fetichizada por la propaganda mediática implementada por el gobierno federal y estatal en torno a que la palma no solo es rentable económicamente, sino también amigable con la naturaleza y favorable para mitigar el cambio climático, lo que ha generado controversias entre los estudiosos del tema, defensores del medio ambiente y los campesinos (Castro, 2009; Castellanos y Jansen, 2015).

En este sentido, distintos autores coinciden en que la historia de la palma de aceite en México empezó en 1952, en la finca La Lima, municipio de Villa Comaltitlán, en la región Soconusco, Chiapas (Fletes y Bonanno, 2015; Castellanos, 2018; Trejo, Valdiviezo y Fletes, 2018; Santacruz y Palacio, 2018). Sin embargo, la historia más relevante con efectos en el campesinado comenzó en la década de los noventa del siglo pasado, cuando el gobierno estatal impulsó la siembra de 4000 hectáreas de palma de aceite en la región y se asentaron algunas empresas extractoras de tipo industrial (Coplade, 1996). Incluso, para el año 2000, los registros del Sistema de Información Agroalimentaria y Pesquera (SIAP) indican que en el estado existían 13861 hectáreas sembradas de palma de aceite, pero solo 2748 se encontraban en producción. Para 2003, en Chiapas se cultivaron 17770 hectáreas en las regiones Soconusco y Selva, con una producción estimada en 144 mil 641 toneladas de racimos de fruta fresca. Este crecimiento corresponde a la política de fomento agropecuario y reconversión productiva aplicada por el gobierno de Pablo Salazar Mendiguchía (2000-2006), que incluyó la transferencia de recursos económicos hacia el sector productivo y agroindustrial a través del Programa Alianza Contigo (Tercer Informe de Gobierno de Chiapas, 2003 y Cuarto Informe de Gobierno de Chiapas, 2004).

EntreDiversidades. Revista de Ciencias Sociales y Humanidades, vol. 8, núm. 1 (16), enero-junio 2021. Páginas: 92 - 118 ISSN-e: 2007-7610. https://doi.org/10.31644/ED.V8.N1.2021.A04 
Mapa 1. Municipios productores de palma de aceite en Chiapas en el ańo 2003

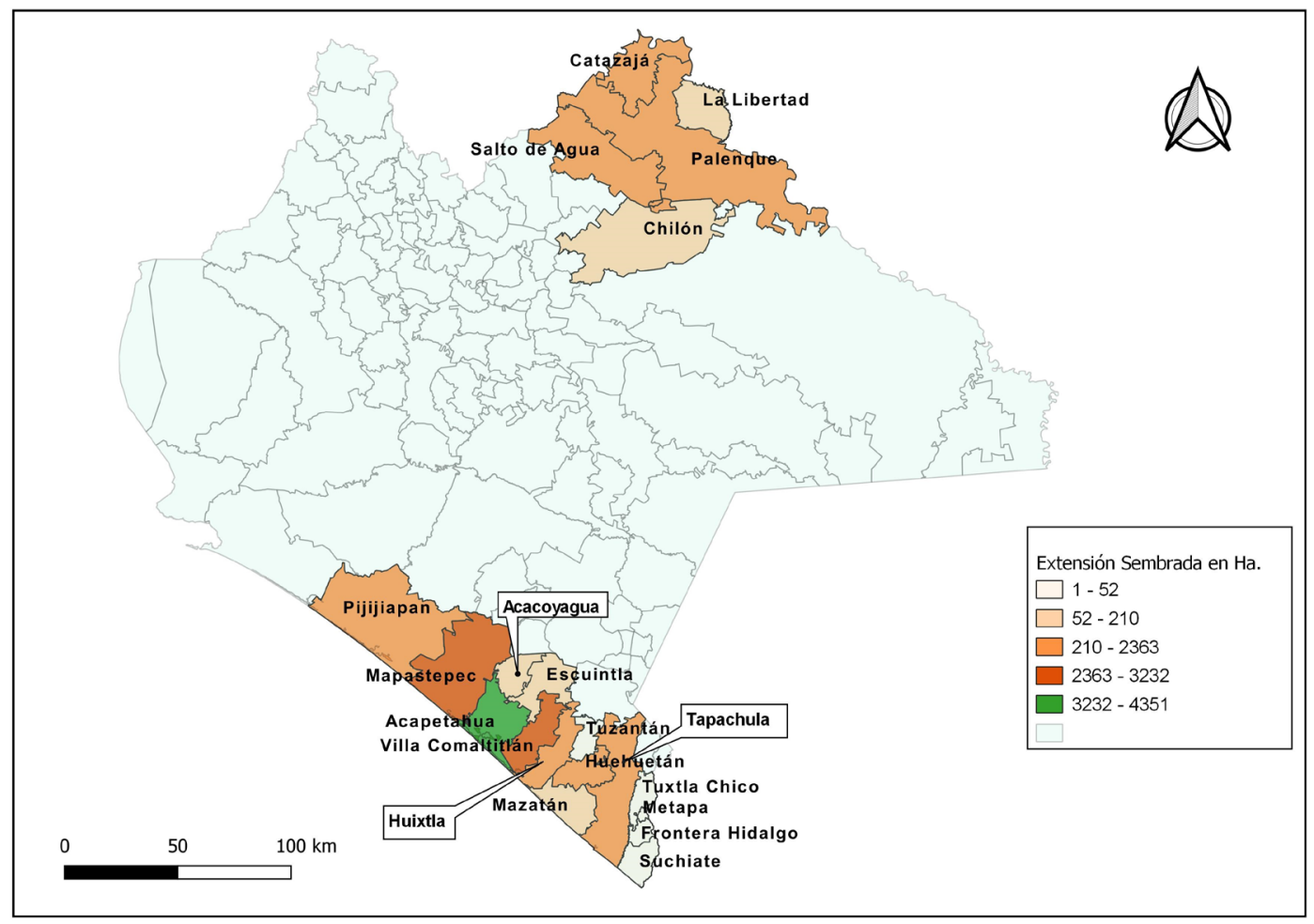

Fuente: Elaborado por Emilio Pérez Pérez con base en CONABIO, 2018, SIAP, 2018

(2 de diciembre de 2019).

Como se puede apreciar en el Mapa 1, para el año 2003 la expansión de la frontera palmícola se había extendido a la zona norte de Chiapas, en algunos municipios de tradición ganadera. A pesar de ello, si bien es cierto que durante el gobierno de Pablo Salazar se apoyó el cultivo de la palma, el verdadero impulso ocurrió durante la administración de Juan Sabines Guerrero (2006-2012). Si nos atenemos a las cifras oficiales generadas por el SIAP, la dinámica de crecimiento de la superficie palmícola sería la que se muestra en el Cuadro 1. 
Cuadro 1. Dinámica de expansión de la palma aceitera en Chiapas, 2000-2012

\begin{tabular}{|c|c|c|c|c|c|c|}
\hline \multirow{2}{*}{ Año } & \multicolumn{2}{|c|}{ Superficie/ha } & \multicolumn{2}{c|}{ Producción } & Precio prom. & Valor producción \\
\cline { 2 - 7 } & Sembrada & Cosechada & Total & Ton/ha & Pesos/ton & (miles de pesos) \\
\hline 2000 & 13861 & 2748 & 51345 & 19 & 480 & 24646 \\
\hline 2001 & 13982 & 6884 & 135696 & 20 & 500 & 67848 \\
\hline 2002 & 17160 & 6884 & 137102 & 20 & 420 & 57583 \\
\hline 2003 & 16793 & 10819 & 200492 & 19 & 748 & 150037 \\
\hline 2004 & 16608 & 12687 & 227309 & 18 & 628 & 142853 \\
\hline 2005 & 16761 & 13865 & 185212 & 13 & 524 & 97032 \\
\hline 2006 & 16789 & 15275 & 229614 & 15 & 659 & 151401 \\
\hline 2007 & 17032 & 15449 & 228215 & 15 & 1173 & 267794 \\
\hline 2008 & 19290 & 16197 & 242616 & 15 & 805 & 195216 \\
\hline 2009 & 22702 & 16211 & 261658 & 16 & 1124 & 294118 \\
\hline 2010 & 33500 & 19902 & 342037 & 17 & 1592 & 544584 \\
\hline 2011 & 38525 & 20887 & 400175 & 19 & 1663 & 665653 \\
\hline 2012 & 46406 & 19981 & 325700 & 16 & 1751 & 570348 \\
\hline
\end{tabular}

Fuente: Elaboración propia con base en Anuario Estadístico de la Producción Agrícola, SIAP, 2019.

Estos datos indican que en el periodo de 2007 a 2012 la superficie sembrada de palma de aceite tuvo un incremento del $172 \%$, casi diez veces más de lo sembrado durante el gobierno de Pablo Salazar. En esta dinámica de crecimiento convergen la política de incentivos del gobierno estatal y federal a través del programa de reconversión productiva (Sexto Informe de Gobierno de Chiapas, 2012), pero también el relanzamiento y transformación del Plan Puebla-Panamá como Proyecto Mesoamérica, y un aumento de los precios de la fruta fresca en el mercado. De hecho, el precio promedio de la fruta pasó de 659 pesos la tonelada en 2006 a 1751 pesos en 2012, un incremento del $265 \%$, el cual se reflejó en un aumento del $400 \%$ en el valor de la producción y seguramente en los ingresos del productor.

Después del gobierno de Sabines se observa un relajamiento en las políticas de fomento al cultivo de la palma. De acuerdo con las cifras del SIAP, durante el periodo de gobierno de Manuel Velasco Coello (2012-2018) no se registraron cambios significativos en la superficie sembrada, incluso hubo una disminución. La superficie sembrada pasó de 48685 hectáreas en 2013 a 45426 en 2018, con una reducción de casi 7\%, mientras que la superficie cosechada aumentó en 14\%, al pasar de 29738 a 38316 hectáreas. Aunque, durante su gobierno, iniciaron operaciones tres plantas procesadoras de aceite de palma en el territorio estatal e inauguró una planta extractora de aceite de palma para el sector social (Cuarto Poder, 2018). La reducción del tamaño de la superficie sembrada reportada por el SIAP coincide con la disminución del precio 
promedio del fruto de palma, que pasó de 1751 pesos la tonelada en 2012 a 1566 pesos en 2018, así como con la escasa promoción del Proyecto Mesoamérica y la búsqueda de otras fuentes de energía. A pesar de todo, para ese tiempo la frontera palmícola ya se había extendió a otras regiones de Chiapas, como se puede ver en el Mapa 2.

\section{Mapa 2. Municipios productores de palma de aceite en Chiapas en el año 2018}

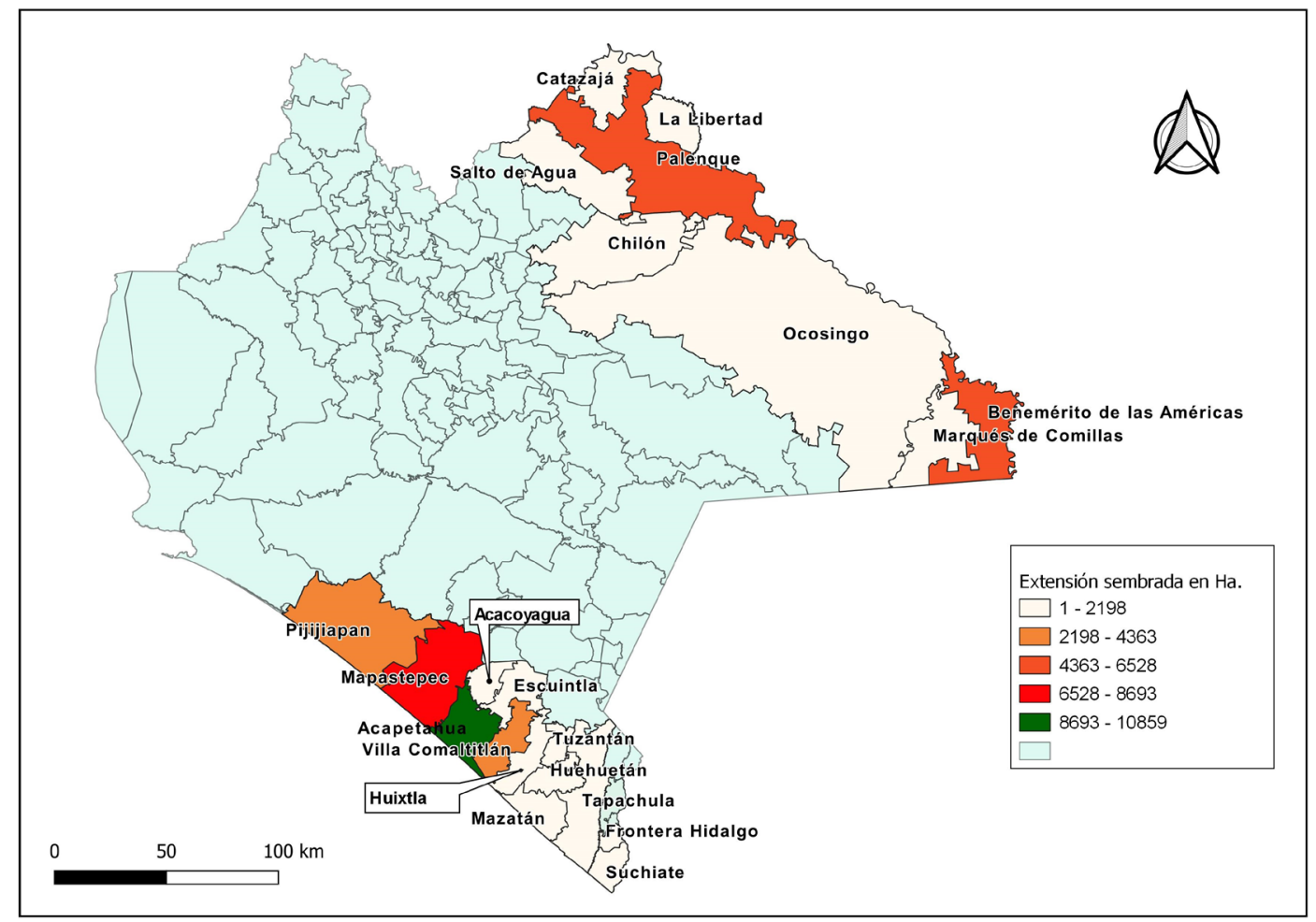

Fuente: Elaborado por Emilio Pérez Pérez con base en CONABIO, 2018, SIAP, 2018

(2 de diciembre de 2019).

Una revisión del Plan Estatal de Desarrollo 2019-2024 permite ver que la palma aceitera forma parte de los diez cultivos más importantes en términos del valor generado en Chiapas, que en 2017 ocupó el octavo lugar, con 778.5 millones de pesos. Sin embargo, al día de hoy no existe mención a este cultivo por parte del gobierno estatal de Rutilio Escandón Cadenas (2018-2024), tampoco está considerado en el Programa "Sembrando Vida", uno de los pilares del gobierno federal para el desarrollo del campo mexicano, lo que indica que la sobrevivencia de los productores y la expansión de este cultivo ahora depende de la dinámica del mercado. 


\section{La región Soconusco, estructura agraria y transformación en el patrón productivo}

De acuerdo con el Censo Agropecuario 2007, en el Soconusco se registraron 55060 unidades de producción rural, con una superficie total de 394452 hectáreas. ${ }^{2}$ Sin embargo, en la Actualización del Marco Censal Agropecuario 2016 la superficie total estimada para dicha región ascendió a 558048 hectáreas, un incremento del $41 \%$ en nueve ańos. De igual manera, las mismas fuentes registran un aumento del $76 \%$ en la superficie destinada a la agricultura, al pasar de 198861 hectáreas en 2007 a 351686 hectáreas en 2016, lo que implica cambios acelerados en el uso del suelo. Para acercarnos a esta cuestión se presenta el Cuadro 2, donde se muestra la estructura agraria de la región y su dinámica en los municipios.

Cuadro 2. Estructura agraria en el Soconusco, 2016

\begin{tabular}{|c|c|c|c|c|c|c|c|}
\hline \multicolumn{7}{|c|}{ Superficie total por municipio y desagregada según tenencia de la tierra } \\
\hline Núm. & Municipio & Total (Ha) & Ejidal & Comunal & Privada & Colonia & Pública \\
\hline 1 & Acacoyagua & 23900 & 17162 & 0 & 6593 & 0 & 146 \\
\hline 2 & Acapetahua & 54514 & 14780 & 0 & 32691 & 0 & 7044 \\
\hline 3 & Cacahoatán & 15599 & 12346 & 0 & 3253 & 0 & 0 \\
\hline 4 & Escuintla & 36300 & 25963 & 0 & 5888 & 0 & 4448 \\
\hline 5 & Frontera Hidalgo & 9199 & 2020 & 0 & 7127 & 0 & 52 \\
\hline 6 & Huehuetán & 29442 & 11239 & 0 & 18197 & 0 & 5 \\
\hline 7 & Huixtla & 36629 & 18796 & 0 & 17760 & 0 & 73 \\
\hline 8 & Mapastepec & 119797 & 73708 & 592 & 40027 & 3055 & 2416 \\
\hline 9 & Mazatán & 34962 & 23266 & 0 & 11628 & 0 & 68 \\
\hline 10 & Metapa & 2219 & 424 & 0 & 1777 & 0 & 18 \\
\hline 11 & Villa Comaltitlán & 42635 & 21755 & 0 & 20683 & 0 & 198 \\
\hline 12 & Suchiate & 22551 & 10544 & 0 & 11663 & 34 & 310 \\
\hline 13 & Tapachula & 91650 & 30057 & 179 & 61225 & 0 & 188 \\
\hline 14 & Tuxtla Chico & 15942 & 3333 & 0 & 12464 & 9 & 137 \\
\hline 15 & Tuzantán & 16943 & 10255 & 0 & 6629 & 8 & 51 \\
\hline 16 & Unión Juárez & 5767 & 3801 & 0 & 1694 & 0 & 271 \\
\hline & Soconusco & 558049 & 279447 & 771 & 259299 & 3106 & 15426 \\
\hline
\end{tabular}

Elaboración propia con base en Actualización del Marco Censal Agropecuario 2016.

INEGI, 2016.

Como se puede apreciar, el $50.2 \%$ de la superficie regional pertenece a la propiedad social (ejidos y comunidades), el $46 \%$ a la propiedad privada y el $3 \%$ a propiedad pública. La mayor superficie censada se concentra en cuatro municipios, que en orden de importancia son: Mapastepec, Tapachula, Acapetahua y Villa Comaltitlán, los cuales en conjunto suman el 55.3\% de la

${ }^{2}$ La misma fuente indica que en Chiapas se registraron 460 mil 820 unidades de producción rural (8 por ciento de las reportadas a nivel nacional), con una superficie total de 3972673 hectáreas.

EntreDiversidades. Revista de Ciencias Sociales y Humanidades, vol. 8, núm. 1 (16), enero-junio 2021. Páginas: 92 - 118 ISSN-e: 2007-7610. https://doi.org/10.31644/ED.V8.N1.2021.A04 
superficie total regional. La composición de la estructura agraria al interior de los municipios es muy variable, destacándose que solo en los municipios de Mapastepec y Tapachula quedan rastros de la tenencia comunal. Sin embargo, la coexistencia de la propiedad social con la privada se traduce en la confluencia de familias campesinas, empresarias, rancheras y finqueras, lo que indica cierto grado de articulación en los procesos productivos y de mercado, al mismo tiempo que muestra la diferenciación económica y social, reflejada en el tamaño de la superficie familiar.

Es importante mencionar que para 2016, de las 558049 hectáreas que conforman la superficie de labor regional, el 63\% se destinaba a la agricultura, el $27 \%$ a la ganadería, el $0.3 \%$ a la actividad forestal, el $1.5 \%$ a otras actividades y el $8.2 \%$ se enmarcó como tierras en descanso y bosques. Además, de las 351685 hectáreas destinadas al uso agrícola, 33\% se destinaba al cultivo de café, $10 \%$ al mango, 9\% al maíz, 9\% a la palma de aceite, 7\% al plátano, 5\% a la cańa de azúcar, $4 \%$ al cacao y el resto a los cultivos de arroz, frijol, soya, ajonjolí, sandía, melón, limón, aguacate, rambután, entre otros (Actualización del Marco Censal Agropecuario, 2016). Es decir, casi el $80 \%$ de la agricultura regional correspondía a cultivos de plantación, orientados principalmente al mercado nacional e internacional. La diversidad de cultivos configura una geografía agrícola regional compleja, que se expresa en la dinámica económica de las familias campesinas. En el Cuadro 3 se muestra la dinámica agrícola de cada municipio.

Cuadro 3. Superficie agrícola por cultivo y municipio, Soconusco, 2016

\begin{tabular}{|l|c|c|c|c|c|c|c|c|c|}
\hline \multicolumn{7}{|c|}{ Cultivos preponderantes por municipio, Soconusco 2016 } \\
\hline \multicolumn{1}{|c|}{ Municipio } & Total (Ha) & Café & Mango & Maíz & Pal/aceite & Plátano & C/azúcar & Cacao & Frijol \\
\hline Acacoyagua & 16029 & 10440 & 2416 & 983 & 189 & 10 & 0 & 217 & 38 \\
\hline Acapetahua & 28493 & 0 & 0 & 1532 & 10673 & 1605 & 490 & 82 & 0 \\
\hline Cacahoatán & 13045 & 10471 & 0 & 1489 & 0 & 0 & 0 & 0 & 1 \\
\hline Escuintla & 26370 & 17026 & 1860 & 1798 & 331 & 11 & 0 & 87 & 66 \\
\hline Frontera Hidalgo & 7165 & 0 & 1087 & 4089 & 0 & 417 & 0 & 53 & 0 \\
\hline Huehuetán & 21276 & 2891 & 5687 & 1655 & 1405 & 2513 & 1739 & 2396 & 0 \\
\hline Huixtla & 25336 & 5318 & 270 & 1133 & 2018 & 40 & 8985 & 816 & 0 \\
\hline Mapastepec & 40472 & 22141 & 986 & 1641 & 5563 & 31 & 40 & 1774 & 5 \\
\hline Mazatán & 22996 & 0 & 5080 & 2209 & 376 & 4759 & 1097 & 243 & 13 \\
\hline Metapa & 1313 & 0 & 261 & 381 & 0 & 248 & 0 & 0 & 0 \\
\hline Villa Comaltitlán & 25585 & 4309 & 2886 & 775 & 7250 & 2329 & 2418 & 792 & 0 \\
\hline Suchiate & 17843 & 0 & 2047 & 1542 & 1153 & 10605 & 0 & 150 & 0 \\
\hline Tapachula & 74698 & 30614 & 10916 & 7280 & 1362 & 3200 & 526 & 804 & 29 \\
\hline Tuxtla Chico & 12172 & 1712 & 201 & 4975 & 0 & 234 & 0 & 1734 & 0 \\
\hline Tuzantán & 13511 & 6413 & 533 & 285 & 124 & 73 & 533 & 3616 & 0 \\
\hline Unión Juárez & 5382 & 3675 & 0 & 498 & 0 & 0 & 0 & 0 & 0 \\
\hline Soconusco & 351686 & 115010 & 34232 & 32264 & 30444 & 26074 & 15828 & 12763 & 152 \\
\hline
\end{tabular}

Fuente: Elaboración propia con base en Actualización del Marco Censal Agropecuario 2016. INEGI.

EntreDiversidades. Revista de Ciencias Sociales y Humanidades, vol. 8, núm. 1 (16), enero-junio 2021. Páginas: 92 - 118 ISSN-e: 2007-7610. https://doi.org/10.31644/ED.V8.N1.2021.A04 
En este cuadro se observa que en 2016 el cultivo de la palma ocupaba el cuarto lugar en la agricultura de la región, resaltando que de las 30444 hectáreas sembradas el 77\% se ubicaba en los municipios de Acapetahua, Villa Comaltitlán y Mapastepec. En conjunto, los tres municipios tuvieron un aumento de la superficie sembrada de palma de $131 \%$ en nueve años, al pasar de 10119 hectáreas en 2007 a 23456 hectáreas en 2016, mientras que la superficie sembrada de mango se redujo en $37 \%$ y la de maíz en $21 \%$ en el mismo periodo. Es decir, la expansión de la palma aceitera está cambiando el patrón de cultivos en la región, y con ello la dinámica de la economía campesina. Incluso algunos productores afirman que la palma de aceite "es un cultivo que ha venido a elevar la economía de las familias productoras, [antes] existían extensiones de terrenos que no se podían aprovechar en época de lluvia porque se inundaban, pero hoy son utilizadas por estas plantaciones" (Gómez, 2019). Sin embargo, algunos estudios refieren que la expansión de la palma en la región ha llegado a profundizar las condiciones de desigualdad social, la dependencia alimentaria y la degradación ambiental (Fletes, Rangel, Oliva y Ocampo, 2013).

Aunque la dinámica de las actividades agrícolas tiene sus propias particularidades en cada municipio, se destaca que en Mapastepec la superficie sembrada de palma pasó de 2372 hectáreas en 2007 a 5563 hectáreas en 2016, y si se retoman los datos registrados por el SIAP para 2018, la superficie sembrada alcanzó las 8556 hectáreas, ${ }^{3}$ un aumento bastante significativo en once años. De hecho, un fenómeno interesante que va en la lógica de la producción y reproducción campesina es la combinación de distintas estrategias productivas, dependiendo del tamaño de la parcela. Al respecto, Román (2015) muestra cómo la actividad ganadera en Mapastepec se mezcló con los cultivos de mango y palma de aceite en distintas proporciones. En su estudio, Román distingue cuatro tipos de productores:

- Tipo A: Se trata del campesino predominante que posee entre 2 y 20 hectáreas; esta superficie le permite tener entre 5 y 30 cabezas de ganado, con lo que obtiene de 10 a 70 litros de leche al día, con una producción de becerros que va de 2 a 10 en el año. Este tipo de campesino tiene en su parcela árboles de mango y, en mayor proporción, palma aceitera.

- Tipo B: Este grupo de campesinos posee entre 20 y 40 hectáreas; con un hato ganadero de 30 a 60 cabezas, que arroja una producción de leche de 70 a 130 litros, con una cosecha de 10 a 20 becerros al ańo para su venta. Este tipo de productores cultivan mango y palma de aceite, en este caso la proporción de palma es menor. Por el tamańo de la parcela, estos campesinos además de utilizar mano de obra familiar contratan fuerza de trabajo y toman en arriendo tierras para siembra de maíz y utilización de pasto para el ganado.

\footnotetext{
${ }^{3}$ El problema de los datos oficiales es que varía de una fuente a otra y no siempre cuadran. Por ejemplo, para el año 2007 el SIAP registró una superficie sembrada de 2941 hectáreas para dicho municipio, mientras que el Censo Agropecuario reportó la cantidad de 2372 hectáreas, una diferencia de 569 hectáreas. Por eso en este apartado se optó por los registros del Censo Agropecuario de 2007 y su Actualización de 2016.
}

EntreDiversidades. Revista de Ciencias Sociales y Humanidades, vol. 8, núm. 1 (16), enero-junio 2021. Páginas: 92 - 118 ISSN-e: 2007-7610. https://doi.org/10.31644/ED.V8.N1.2021.A04 
- Tipo C: Este tipo de productores poseen entre 40 y 60 hectáreas, con una población bovina de 60 a 90 cabezas. Esto hace posible la producción de leche entre 130 a 220 litros diarios. En este grupo, predomina el cultivo del mango frente a la palma aceitera.

- Tipo D: En este tipo de productores se agrupan ejidatarios y propietarios privados. Es interesante, en este caso, la combinación de ambos tipos de propiedad en una sola familia. Poseen entre 80 y 160 hectáreas, y un hato ganadero de 90 y 100 bovinos. Este grupo produce entre 220 y 280 litros de leche al día y obtienen entre 40 y 60 becerros al año. También estos productores cultivan mango y palma de aceite, compran y venden ganado, arriendan la tierra y llevan a cabo proceso de engorda del ganado.

Lo anterior muestra cómo el cultivo de palma tiene varias modalidades en el sector campesino que reflejan las estrategias de reproducción social en el mercado capitalista. En el caso del campesino tipo A, la reducida cantidad de tierras induce a una mayor actividad en palma aceitera, donde el beneficio resultante de una hectárea de palma es mayor que una dedicada a la ganadería, o a otros cultivos de menor precio en el mercado. A este tipo de campesinos nos referimos en los siguientes apartados.

\section{La rentabilidad de la palma de aceite desde la perspectiva campesina}

En el Soconusco operan siete empresas extractoras de aceite de palma, cuatro corresponden al capital privado (La Lima, El Desengaño, Agroimsa y Propalma) y tres a organizaciones campesinas (Bepasa, Zitihualt y La Primavera). ${ }^{4}$ De las cuatro empresas privadas, Promotora de Palma del Soconusco SAPI de CV (ProPalma) y Agroindustrias de Mapastepec (Agroimsa) pertenecen a corporativos de la industria aceitera nacional. La primera forma parte del Grupo ProPalma, que aglutina a tres empresas más: Plantaciones del Soconusco, que posee alrededor de 600 hectáreas de palma distribuidas en tres ranchos productivos — Santa Matilde y El Norteño, en Villa Comaltitlán, y San Carlos, en Acapetahua_; Oleosur, una refinería de aceites vegetales ubicada en Coatzacoalcos, Veracruz; y Bionermex, una planta productora de biodiesel ubicada en Lázaro Cárdenas, Michoacán (Propalma, 2019). La segunda es parte del Grupo Oleopalma, que opera en Mapastepec, Marqués de Comillas y Palenque en Chiapas y Jalapa, en Tabasco, conjuntamente con las empresas "Palmicultores de San Nicolás" y "Palmicultores La Sombra". Este corporativo forma parte del Grupo Oleomex, "un conglomerado de 15 empresas que abarcan desde el establecimiento y mantenimiento de plantaciones, hasta el procesamiento industrial, refinación de aceites y su comercialización con la industria alimentaria y farmacéutica" (Oleopalma, 2019).

Estos corporativos forman parte de la Asociación Nacional de Industriales de Aceites y Mantecas Comestibles (ANIAME), donde concurren las grandes empresas agroindustriales como Cargill y Dupont, los cuales representan los intereses de la industria agroalimentaria global y juegan un papel importante en el proceso de financiarización de la economía. De esta manera, las

${ }^{4}$ La Lima inició actividades en 1970, El Desengaño en 1994, Agroimsa en 2001, Propalma en 2002, Bepasa en 1995, Zitihualt en 2013 y La Primavera en 2015 (Mazariegos, Águila, Martínez y Arévalo, 2014; Trejo, Valdiviezo y Fletes, 2018).

EntreDiversidades. Revista de Ciencias Sociales y Humanidades, vol. 8, núm. 1 (16), enero-junio 2021. Páginas: 92 - 118 ISSN-e: 2007-7610. https://doi.org/10.31644/ED.V8.N1.2021.A04 
empresas extractoras de aceite se articulan, por un lado, con el mercado de valores de Rotterdam, Holanda, donde se fijan los precios del aceite crudo de palma, por otro, con los campesinos productores del fruto. Este tipo de articulación entre la agroindustria y los campesinos no es nada nuevo en el Soconusco; sin embargo, la dinámica de producción de la palma de aceite está generando cambios sustanciales en su relación con el mercado y con la naturaleza.

En los siguientes párrafos se presentan algunos testimonios de ejidatarios que dan cuenta de la dinámica de producción de la palma de aceite, la rentabilidad del cultivo y su articulación con las empresas agroindustriales. Al respecto, don Samuel comenta: "hoy corté cinco toneladas [de fruta] en una parcela de siete hectáreas, pagué como 2 mil pesos por el corte. Tengo cuatro jornaleros y a cada uno le doy 200 pesos el día, más mil pesos de flete y mi día. De ganancia me quedó como mil pesos por tonelada" (Entrevista a Samuel, La Vainilla, Mapastepec, 27/06/2017). Don Samuel empezó sembrando ocho hectáreas de palma en 1993, cuando su actividad principal era la ganadería y la producción de maíz, pero los apoyos otorgados por el gobierno y los precios favorables en el mercado lo llevaron a expandir el cultivo en sus 25 hectáreas, convirtiéndose en su actividad principal. En el mes de junio de 2017 realizó cuatro cortes de fruta y cosechó 20 toneladas en total ( 0.8 ton/ha), las cuales vendió con Agroimsa a un precio de 1696 pesos la tonelada, obteniendo un ingreso bruto de 33920 pesos. Sin embargo, al descontar 8 mil pesos desembolsados por el corte y fletes, y 7200 pesos por concepto de pago de salarios a cuatro jornaleros por el mantenimiento de las plantaciones (150 pesos el día por dos semanas de trabajo), sus ingresos netos se redujeron a 18720 pesos, un beneficio de 748 pesos por hectárea en un solo mes.

En el mismo sentido, don Narciso refiere: "en un día de corte obtuve siete toneladas de fruta [en siete hectáreas], gasté alrededor de 3 mil pesos, incluyendo pago de corte, acarreo, subida al camión, transporte a la empresa y mi gasolina. Me salieron 11 mil pesos, fueron como 8 mil pesos de ganancia” (Entrevista a Narciso, Tzinacal, Huixtla, 26/06/2017). Don Narciso inició cultivando 2.5 hectáreas de palma en 2007, dos años después de que el huracán Stan dañara sus plantaciones de mango y de maíz, pero al ver los apoyos gubernamentales hacia este cultivo y el bajo precio del mango decidió expandir el cultivo de palma a sus siete hectáreas, colocándose como su principal sustento familiar. En junio de 2017 efectuó dos cortes de fruta, alcanzando 14 toneladas en total ( 2 ton/ha), las cuales vendió con Propalma a un precio de 1593 pesos la tonelada, consiguiendo un ingreso bruto de 22302 pesos. Pero, al descontar sus gastos de 2800 pesos por el corte de fruta (200 pesos/ton), 560 pesos por acarreo al camión (40 pesos/ton), 2380 pesos de transporte para la empresa (170 pesos/ton), 100 pesos de gasolina de su motocicleta y 4200 pesos por pago de salarios a tres trabajadores por mantenimiento de las plantaciones (700 pesos por semana a cada uno, por dos semanas), sus ingresos netos se redujeron a 12262 pesos al mes, un beneficio de 1751 pesos por hectárea.

Por su parte, don Armando expresa: "en junio hice dos cortes en las veinte hectáreas que tengo, en el primero corté 18 toneladas y en el segundo 32. Lo vendí con Agroimsa a 1618 pesos la tonelada. Ahorita es cuando ya empieza a subir la producción" (Entrevista a Armando, Mapastepec, 28/06/2017). Don Armando incursionó en la actividad de la palma en 2009, con la siembra de cinco hectáreas, cuando su actividad primordial era la ganadería. Posteriormente,

EntreDiversidades. Revista de Ciencias Sociales y Humanidades, vol. 8, núm. 1 (16), enero-junio 2021. Páginas: 92 - 118 ISSN-e: 2007-7610. https://doi.org/10.31644/ED.V8.N1.2021.A04 
el alza del precio de la fruta lo impulsó a expandir el cultivo en quince hectáreas más, y aunque todavía practica la ganadería extensiva, sus ingresos más fuertes provienen de la producción palmícola. En junio, por la venta de las 50 toneladas (2.5 ton/ha) obtuvo un ingreso bruto de 80 900 pesos. Sin embargo, al descontar el pago de 8200 pesos a siete trabajadores asalariados por el corte y acarreo del fruto (cuatro cortadores y tres acarreadores, los primeros cobraron 140 pesos por tonelada y los segundos 200 pesos por día), 10000 pesos por el transporte del producto a la empresa (200 pesos por tonelada), 10800 pesos por pago de salarios a tres jornaleros fijos (150 pesos por día) para el mantenimiento del palmar, sus ingresos se redujeron a 51900 pesos en ese mes, un beneficio de 2595 pesos por hectárea. Para don Armando, este nivel de ingresos es lo que hace que la producción de palma sea más rentable que otros cultivos, incluso que la ganadería, de donde obtenía alrededor de 5000 pesos semanales por la venta de leche.

Para dimensionar la rentabilidad de la palma se debe tomar en cuenta que los rendimientos no son constantes en todo el año. En los meses de diciembre, enero, febrero, marzo, abril y mayo los rendimientos son bajos, mientras que en junio, julio y agosto ya con la temporada de lluvia la producción empieza a mejorar, por lo que, para septiembre, octubre y noviembre la producción alcanza su nivel máximo. Por ejemplo, nos dice don Samuel, "si en la temporada baja corto cinco toneladas, cuando empiezan las lluvias llego a cortar hasta diez, pero para septiembre o noviembre puedo llegar a cortar hasta veinte toneladas dependiendo del tiempo y de la lluvia" (Entrevista a Samuel, La Vainilla, Mapastepec, 27/06/2017). Para dońa Antonia, el ciclo de lluvias es vital para mantener cierto nivel de producción, por eso "el año pasado que no llovió mucho todas mis palmas estaban tristes y disminuyó la producción” (Entrevista a Antonia, Mapastepec, 27/06/2017). A decir de los campesinos, las áreas más productivas son aquéllas que anteriormente se inundaban en temporadas de lluvia.

Otro de los aspectos que cabe destacar es el uso fertilizantes químicos en las plantaciones de palma, muchos de los productores recurren a esta práctica una o dos veces al año para compensar el grado de fertilidad del suelo. Al respecto, don Armando expresa: "nosotros ahorita estamos aplicando medio kilo de triple 17 por planta, se hace con la técnica del goteo. Este año me costó 350 pesos la bolsa de 50 kilos" (Entrevista a Armando, Mapastepec, 28/06/2017). Para dicho productor, la fertilización ha sido muy importante para incrementar la producción en sus veinte hectáreas, las cuales han alcanzado un rendimiento de alrededor de 25 toneladas por hectárea. En su caso, cada hectárea cuenta con 135 plantas y las fertiliza cada seis meses, suministrando 2.7 toneladas de fertilizantes químicos al año. Esta práctica muestra una mayor integración de los campesinos al mercado y a las cadenas agroindustriales proveedoras de insumos químicos.

En el mismo sentido, los precios del mercado tampoco son constantes. Por ejemplo, en los primeros tres meses del ańo 2017 los precios pagados por Agroimsa a los productores se situaron en un promedio de 2 mil pesos por tonelada de fruta fresca. Pero en abril y mayo el precio empezó a descender, hasta llegar a 1600 pesos la tonelada en el mes de junio y 1500 pesos en el mes noviembre. Es decir, los precios de fruta fresca tuvieron una caída del $25 \%$ en el transcurso del año, lo que se traduce en una disminución de los ingresos del productor. Se trata del juego de la oferta y la demanda, pero también de la volatilidad de los precios generada por la especulación financiera de las grandes empresas en el mercado nacional e internacional. A pesar de esto, "en todos los años

EntreDiversidades. Revista de Ciencias Sociales y Humanidades, vol. 8, núm. 1 (16), enero-junio 2021. Páginas: 92 - 118 ISSN-e: 2007-7610. https://doi.org/10.31644/ED.V8.N1.2021.A04 
que llevamos produciendo palma no hemos tenido pérdida, siempre ha sido beneficio, aunque algunas veces ha sido muy poco" (Entrevista a Antonia, Mapastepec, 27/06/2017).

Por otra parte, la producción de la palma de aceite está cambiando la dinámica de contratación de trabajadores asalariados (cortadores, picadores, cargadores, recogedores de fruto y choferes). Se puede decir que el puesto de cortador es el mejor cotizado, pues de este depende que el fruto cumpla con los estándares de calidad que exige la empresa, quien puede ganar entre 200 y 400 pesos en una jornada de trabajo de 6 a 8 horas al día. Pero si su trabajo es a destajo, su salario se puede triplicar. Al respecto, don Nicolás nos dice:

Por cada racimo que corto me pagan 4 pesos, eso porque las plantaciones no están muy altas, corto mínimo 100 racimos de fruta al día, máximo de 250, 300 o hasta 400 racimos en un día. Pero eso, cuando todas las plantas tienen fruta, así he llegado a ganar hasta mil pesos en un día. Descontando los 150 pesos que le pago a mi ayudante para que él vaya picando las hojas. Ahora, cuando las plantas ya pasan los 15 metros de altura me pagan a 6 pesos por racimo, porque el corte es más lento (Entrevista a Nicolás, Villa Comaltitlán, 24/10/2018).

Esto ha llamado la atención de algunos jornaleros que han pretendido ocupar el puesto, aunque se requiere de mucha preparación, pues es el trabajo con mayores riesgos de accidente. Aun así, "el corte de palma es un buen trabajo y me permite estar en mi comunidad, tener un ingreso seguro, sin tener que migrar a buscar trabajo a otro lado" (Entrevista a Josué, Villa Comaltitlán, 25/10/2018).

Así pues, desde la perspectiva campesina el cultivo de palma es más rentable que otros cultivos, incluso que la ganadería, porque les ha permitido incrementar sus ingresos económicos, sobre todo a las familias que tienen más de cinco hectáreas, generando procesos de desigualdad económica y social al interior de los ejidos. Se trata de una rentabilidad que se expresa en un ingreso monetario cada quince días, en la contratación de trabajadores asalariados y en la posibilidad de adquirir un "camioncito, una camioneta pickup y dos o tres motocicletas. Antes no se veía eso, antes había mucha gente con terreno, pero no todos tenían dinero para comprar ganado y ahí se quedaban. Ahora varios productores que solo tenían dos o cinco hectáreas tienen diez, veinte o más, hay empleo y se ha reactivado la economía en la región" (Entrevista a Armando, Mapastepec, 28/06/2017).

Sin embargo, aunque la base de la rentabilidad se encuentra en la dinámica de los precios en el mercado, y este en el dinamismo de la oferta y la demanda, que por ahora es favorable, uno de los elementos más importantes del cultivo de la palma de aceite es que el tiempo de cosecha se realiza cada quince días. Esto, en relación con la producción de granos básicos como el maíz, frijol, o con otros cultivos como café, mango o caña de azúcar, que tienen como base una estacionalidad de cosecha trimestral, semestral o anual. Es decir, el cultivo de la palma, en tanto cambio de patrón de cultivo, ha llegado a instaurar un nuevo ciclo de producción-cosecha quincenal en la agricultura campesina, $y$, por lo tanto, una nueva dinámica en la periodicidad de los ingresos monetarios de las familias.

Este es uno de los cambios más importantes en la dinámica de la economía campesina porque implica una articulación mayor de los campesinos con la agroindustria, no solo a través de los

EntreDiversidades. Revista de Ciencias Sociales y Humanidades, vol. 8, núm. 1 (16), enero-junio 2021. Páginas: 92 - 118 ISSN-e: 2007-7610. https://doi.org/10.31644/ED.V8.N1.2021.A04 
precios del fruto de la palma cotizado en la bolsa de valores de Rotterdam, sino también en el consumo de insumos químicos para la producción. Una articulación que implica una mayor intensificación de la explotación de la tierra y la naturaleza, y su consecuente degradación, así como la reducción del tiempo de reproducción del capital en el campo.

\section{Cambios en la economía campesina en torno a la adopción y desarrollo de la palma de aceite}

En sintonía con lo anterior, para fines ilustrativos del proceso de adopción y desarrollo de la palma de aceite en el Soconusco, se presenta la experiencia de los campesinos del ejido Abraham González (en adelante AG), municipio de Mapastepec. El ejido se fundó en 1979 con una dotación de 1140 hectáreas para 109 beneficiarios, correspondiendo una parcela de 10 hectáreas por familia. En sus inicios sembraron maíz, frijol y arroz, los cuales destinaban a su alimentación y a la venta de los excedentes. Al respecto, don Jeremías expresa: "cuando empezamos a trabajar estas tierras cosechábamos como 5 toneladas de maíz por hectárea, con dos hectáreas producía uno bastante y sobraba para vender" (Entrevista a Jeremías, AG, 29/11/2019).

En la década de 1980, las actividades que prometían mayores ingresos económicos para los campesinos eran el cultivo de tabaco, pastos y ganadería, que en distintos grados tenían apoyo del gobierno federal. En este sentido, don Ezequiel comenta: "yo destinaba mi parcela para sembrar maíz y sacaba buena producción, el kilo de maíz estaba en 1.20 pesos, pero de ahí bajó la producción y empecé a sembrar tabaco" (Entrevista a Ezequiel, AG, 24/01/2020). Aunque una parte de los ejidatarios optó por la ganadería, la mayoría decidió sembrar tabaco debido a los apoyos que ofrecía Tabamex, organismo paraestatal que proporcionaba todos los insumos necesarios para las plantaciones, y al terminar la cosecha se los descontaban. "Había veces que nos iba bien, por ejemplo, en 1988 sembré cuatro hectáreas de tabaco y el precio estuvo bueno, cuando fui a liquidación me faltaron 80 pesos para un millón, era bastante dinero. Con eso compré ocho toretitos y empecé con la ganadería" (Entrevista a Ezequiel, AG, 24/01/2020). En varios casos, a diferencia de la actividad ganadera, el cultivo de tabaco permitía destinar una parte de la parcela para la siembra de maíz, frijol u otros cultivos.

Para 1990 los campesinos dejaron de cultivar tabaco "porque el gobierno cerró Tabamex y se lo vendió a Cigarrera La Moderna. Vino La Moderna y nos dijo que todos sembráramos las 10 hectáreas, nos dio todos los insumos también, pero al final de la cosecha no nos pagó. Eso nos enojó mucho y acordamos no volver a sembrarlo" (Entrevista a Ezequiel, AG, 24/01/2020). Frente a esta situación, algunos eligieron la ganadería, otros prefirieron sembrar sandía para seguir cultivando un poco de maíz o arroz: "Sembramos sandía unos años, pero el coyotaje era bastante fuerte, venían a comprarnos la sandía acá y nos decían que nos iban a pagar en una semana. Eso fue otro problema porque no venían luego con el dinero" (Entrevista a Ezequiel, AG, 24/01/2020). El cierre de Tabamex y la dinámica del intermediarismo local terminaron orientando a los campesinos a la siembra de pastos y cría de ganado.

Las familias que desde principios de los ochenta habían optado por la ganadería se enfrentaban a otros problemas. $\mathrm{Al}$ respecto, don Lucho nos dice: "En 1984 empezaron los bancos a extender

EntreDiversidades. Revista de Ciencias Sociales y Humanidades, vol. 8, núm. 1 (16), enero-junio 2021. Páginas: 92 - 118 ISSN-e: 2007-7610. https://doi.org/10.31644/ED.V8.N1.2021.A04 
créditos pequeños de ganado y la gente empezó a acomodarse [a organizarse], sembraba maíz o arroz y una parte para ganado. Pero para 1987 los bancos dieron créditos amplios para 10 o 15 vacas, entonces el ejido también se fue haciendo ganadero" (Entrevista a Lucho, AG, 25/01/2020). Un campesino dedicado a esta actividad llegó a tener "como 20 vacas en pie de cría y ganado de engorda, de tal manera que ya no alcanzaba las 10 hectáreas, pagaba pastura y como los intereses de los bancos eran variables, no pudimos prosperar. En 1987 agarramos un crédito al 8\%, pero para 1990 ya eran más los intereses que el capital” (Entrevista a Lucho, AG, 25/01/2020).

Estos créditos fueron otorgados a grupos de campesinos por el Banco Nacional de Crédito Rural del Istmo y por Multibanco Comermex. En el ejido existieron tres grupos de al menos diez ejidatarios cada uno. Algunos recuerdan que en 1990 llegaron "los ingenieros que administraban los créditos a decirnos que teníamos que pagar, porque ya era más lo que debíamos que lo que teníamos en nuestro corral. 'Es necesario que paguen, vendan todo su ganado y paguen, si no pagan les van a venir a embargar', dijo" (Entrevista a Lucho, AG, 25/01/2020). Por temor a las amenazas, uno de los grupos vendió todo su ganado y fue a depositar el dinero al banco como pago de capital. Para su sorpresa, tres meses después llegó un documento del banco solicitando que fueran a pagar su deuda. "Nos enojamos mucho y fuimos a ver al ingeniero, 'y el dinero que pagamos, pues, ingeniero ¿dónde está?'. 'Pues eso no es cosa nuestra, viene de allá arriba, y si no pagan se va a hacer más grande la deuda', dijo” (Entrevista a Lucho, AG, 25/01/2020).

La incertidumbre y el coraje hicieron que uno de los grupos que no había pagado el crédito programara una reunión con uno de los encargados de su banco e invitó a todos los deudores. "Vino un ingeniero de Comermex, y ‘`cómo están ustedes?', nos dijo. 'Nosotros ya vendimos el ganado', pero ‘¿tienen el dinero?', dice. 'No', le dijimos, 'ya lo depositamos'. 'Ya los amolaron', dijo, 'el gobierno ya congeló las cuentas, cayeron en cartera vencida, ustedes ya no iban a pagar'” (Entrevista a Lucho, AG, 25/01/2020). De esta manera, diez familias quedaron en la quiebra, por lo que su estrategia de sobrevivencia fue sembrar pequeñas superficies de maíz, dar rentado sus pastizales y trabajar con otros ganaderos bajo la modalidad de "al partir", es decir, un pago en especie por el arrendamiento de pastizales.

En este contexto, al ejido llegaron "ingenieros" del gobierno a promocionar la palma de aceite. Los primeros interesados fueron las familias de ganaderos que se encontraban en quiebra. "En 1991 yo no andaba por acá y mis muchachos solicitaron plantas para las diez hectáreas, pero nada más nos dieron para tres, ya en 2005 fue que vino la ampliación de la palma, porque antes, cuando nosotros empezamos, no tenía mercado, no había extractora de aceite cerca" (Entrevista a Lucho, AG, 25/01/2020). Los iniciadores del cultivo refieren que las primeras cosechas empezaron alrededor de 1995, pero no sabían qué hacer con el fruto. Quienes tenían vehículo trataron de comercializarlo en Villa Comaltitlán, aunque los bajos precios llevaron a algunos a destruir sus plantaciones.

"Nosotros dejamos nuestra plantación, el que tenía su carrito compraba la fruta, pero nos daba lo que quería, 200 o 400 pesos, a veces mejor no lo cortábamos. Ya en el año 2000 empezó esta empresa de Agroimsa y empezamos a vender ahí, pero muy barato, no era negocio, a 300 pesos la tonelada" (Entrevista a Lucho, AG, 25/01/2020). Para estos ańos, al interior de las plantaciones de palma había pastos y ganado, pero conforme fue subiendo el precio de la fruta "le quité el ganado y empecé a cultivar la palma, pues había que cortarlo a cada 15 días. Después

EntreDiversidades. Revista de Ciencias Sociales y Humanidades, vol. 8, núm. 1 (16), enero-junio 2021. Páginas: 92 - 118 ISSN-e: 2007-7610. https://doi.org/10.31644/ED.V8.N1.2021.A04 
fue subiendo de precio, llegó hasta 500 pesos, de ahí a 700 y así. Tuvieron que pasar muchos años para que se pusiera bueno el negocio" (Entrevista a Lucho, AG, 25/01/2020).

En la década de los noventa y hasta el primer lustro del siglo XXI, en el ejido la actividad principal era la ganadería, seguido por los cultivos de palma y mango, y en menor medida de maíz. Al respecto, don Ezequiel expone: "Llegué a tener 70 cabezas de ganado, tenía que rentar pastizales con compañeros, había ordeña, sacaba 100 o 150 litros de leche al día, le vendíamos a queseros de Mapastepec, nos pagaban a la semana. De ahí salía para comer, para algunas cositas de la casa y para medicinas del ganado" (Entrevista a Ezequiel, AG, 24/01/2020). Aunque lo fuerte para su economía familiar era la venta de ganado en pie, por ejemplo, "las crías se vendían a 2000 o 2500 pesos, dependiendo de las que hubieran, a veces 10, 15 o 20, ya era buen ingreso" (Entrevista a Ezequiel, AG, 24/01/2020).

Sin embargo, a partir de 2005, "cuando el precio [del fruto de la palma] mejoró y los primeros que sembraron incrementaron sus ingresos, toda la gente empezó a vender sus animalitos y a sembrar palma” (Entrevista a Ismael, AG, 29/11/2019). Además fue un tiempo en que el gobierno “te regalaba las plantas y te daba apoyo para sembrar, mantenimiento, flete y fertilizar. Fueron tres años que me apoyaron, yo recibí 15 mil pesos por tres años, por 6 hectáreas que sembré. En realidad era poco, pero fue un gran apoyo para el arranque" (Entrevista a Jeremías, AG, 30/11/2019). De esta manera, el alza del precio de la fruta, el apoyo gubernamental, el encarecimiento de los insumos para ganado y los remanentes de inundaciones provocados por el huracán Stan en 2005 generaron las condiciones para la expansión del cultivo de palma en el ejido.

De acuerdo con los productores, entre 2010 y 2012 el precio de una tonelada de fruta fresca llegó hasta 2100 pesos, es el precio más alto al que han vendido la fruta, pero después de ese periodo el precio ha sido muy variable, llegando a descender hasta 1100 pesos la tonelada. A pesar de la volatilidad del precio y del retiro de los apoyos directos al productor por parte del gobierno estatal y federal, la palma de aceite se convirtió en el cultivo preferido de la mayoría de los campesinos del ejido. Muchos consideran que "la palma es buena porque, aunque sea poco da, por ejemplo, ahorita la producción es muy baja, estoy sacando seis toneladas cada 15 días en las diez hectáreas, pero hay veces que he llegado a sacar hasta 30 toneladas, ahí nos va bien” (Entrevista a Ezequiel, AG, 24/01/2020).

En este ejido, son pocas las familias que aún continúan con la actividad ganadera en menor escala, complementándola con los cultivos de mango o maíz. Son familias que se resisten a dejar lo que en algún momento fue su actividad principal, pero también porque algunos consideran que la palma es más agresiva con la naturaleza. Al respecto, don Lucio comenta: "aunque la palma es una fuente favorable de ingresos, yo no le quise entrar porque me han dicho que una planta consume entre 40 y 70 litros de agua al día, ocupa mucho fertilizante químico y daña al medio ambiente. Por eso, seguimos con la ganadería y cultivos básicos" (Entrevista a Lucio, AG, 26/06/2018).

Para los campesinos del ejido, la producción de palma de aceite llegó a dinamizar la economía familiar, ejidal y regional en distintas proporciones, no solo por el incremento progresivo de sus ingresos, sino también por los incentivos otorgados por el gobierno federal hasta el año 2012. Esto contribuyó a generar empleos especializados fuera del núcleo familiar y ejidal,

EntreDiversidades. Revista de Ciencias Sociales y Humanidades, vol. 8, núm. 1 (16), enero-junio 2021. Páginas: 92 - 118 ISSN-e: 2007-7610. https://doi.org/10.31644/ED.V8.N1.2021.A04 
además de crear un grupo de transportistas dedicados al traslado del producto a las empresas comercializadoras, principalmente a Agroimsa. Además, la dinámica de cosecha de la palma cada quince días llegó a facilitar la disposición de efectivo para satisfacer sus necesidades inmediatas, mejorar su vivienda, cubrir sus gastos en el ejido, solicitar créditos en los bancos y consumir otras mercancías, dependiendo del tamaño de su parcela y del nivel de producción. Sin embargo, aún con dichas virtudes económicas, el cultivo de la palma también llegó a generar una relación más estrecha con el mercado, tanto en la producción como en el consumo, donde la volatilidad de los precios, la incertidumbre y la especulación financiera pueden llevarlos a experimentar cambios repentinos en la dinámica de su economía familiar y, por lo tanto, en sus condiciones de vida.

\section{Reflexión final}

De acuerdo con los testimonios presentados, el mundo campesino se ha ido transformando en sintonía con los procesos que devienen del cambio de la economía nacional y mundial. En este sentido, la adopción y expansión del cultivo de la palma de aceite en el contexto de la globalización neoliberal como una vía para la obtención de ingresos monetarios está cambiando la lógica productiva y organizativa de la economía campesina. En este proceso, la población campesina palmicultora ha sido integrada de una manera más concreta a las cadenas agroindustriales nacionales y globales, las cuales, con el apoyo del Estado, han logrado instaurar un nuevo ciclo de producción-cosecha quincenal en la agricultura campesina, acercándola aún más a las turbulencias de la especulación financiera. Aunque para los campesinos esto ha significado un aumento en sus ingresos que se expresa en el mejoramiento de la vivienda y compra de vehículos, su integración a la lógica del mercado, hacia adelante con la venta de materias primas y hacia atrás con la adquisición de insumos químicos, significa dinamizar la reproducción del capital en el campo a base de la intensificación de la explotación de la fuerza de trabajo, de la tierra y la naturaleza.

Incluso algunas familias han ahorrado y han adquirido otra parcela sin cultivar o con cultivo de palma, pero cada vez esto es más difícil para los pequeńos productores, dado el incremento del valor de la tierra: por ejemplo, en 2005 una hectárea sembrada con palma tenía un precio de 60 mil pesos, y en enero de 2020 esta había alcanzado los 180 mil pesos, un incremento del $200 \%$. Esto es indicativo de que el cultivo de la palma aceitera así como incrementa los ingresos de algunos campesinos, también genera procesos de exclusión en otros, provocando cierto dinamismo del mercado de tierras en la región. Sin embargo, la profundización de este tema queda pendiente de investigar.

Se puede decir que el factor más importante para la rentabilidad de la palma en las parcelas campesinas es la extensión de la superficie cultivada. Sobre la base de la extensión y la condición de los suelos, se añade el manejo tecnológico y los precios del mercado. Además, para quienes tienen mayor extensión de tierra todavía pueden combinar el cultivo de palma con actividades complementarias, fortaleciendo un poco más su economía campesina.

De manera general, al interior de las comunidades campesinas del Soconusco prevalece una percepción aparentemente positiva sobre las bondades de las plantaciones de palma, aunque, de manera particular también existen percepciones que se resisten al nuevo patrón productivo,

EntreDiversidades. Revista de Ciencias Sociales y Humanidades, vol. 8, núm. 1 (16), enero-junio 2021. Páginas: 92 - 118 ISSN-e: 2007-7610. https://doi.org/10.31644/ED.V8.N1.2021.A04 
pero reconocen que dadas sus bondades económicas es muy difícil dar marcha atrás. Además, en algunos lugares empiezan a emerger otros aspectos no tan favorables del cultivo, como la escasez del agua en tierras poco profundas y el intermediarismo local. A ello se agrega que desde el año 2012 el gobierno estuvo reduciendo los apoyos directos al productor, y en la presente Administración no se ha incluido en el programa Sembrando Vida. En estas condiciones, los palmicultores están a expensas de la dinámica del mercado y de los intereses del capital privado, que, como lo muestra la historia de la región, este puede ser bondadoso en su momento de auge, pero en los tiempos de crisis deja que el mayor costo lo absorba el productor, y eso para muchos puede significar la ruina.

\section{Bibliografía citada}

Acosta, Irma (2006). Influencia del neoliberalismo en la dialéctica del campesinado. Experiencia de México. [edición electrónica] México: Eumet.net. Disponible en: www.eumed.net/ libros/2006b/ilar/ (Consultado el 16 de abril de 2020).

Bartra, Roger (1972). "Campesinado y poder político en México: Un modelo teórico". Revista Mexicana de Sociología, 34 (3/4), pp. 659-684. También disponible en: https://doi. org/10.2307/3539254

Calva, José Luis (1988). Los campesinos y su devenir en las economías de mercado. México: Siglo Veintiuno Editores.

Calva, José Luis (2019). "La economía mexicana en su laberinto neoliberal”. El Trimestre económico, 86 (343), pp. 579-622. También disponible en: https://doi.org/10.20430/ete.v86i343.921

Castellanos, Antonio (2018). "Palma de aceite en tierras campesinas: la política de las transformaciones territoriales en Chiapas, México". Revista Pueblos y fronteras Digital, 13 (-), pp. 1-34. Disponible en: https://doi.org/10.22201/cimsur.18704115e.2018. v13.357 (Consultado en febrero y octubre de 2020).

Castellanos, Antonio y Jansen, Kees (2015). "Oil Palm Expansion Without Enclosure: Smallholders and Environmental Narratives". The Journal of Peasant Studies, 42 (34), pp. 791-816. Disponible en: https://doi.org/10.1080/03066150.2015.1016920 (Consultado en octubre de 2020).

Castro, Gustavo (2009). "México: Los efectos de la palma africana”. GlobalHoy, núm. 22, sección 040. Disponible en: http:/www.gloobal.net/iepala/gloobal/fichas/ficha. php?id=11551\&entidad=Textos\&html=1 (Consultado el 15 de noviembre de 2019).

Chayanov, Alexander (1974). La organización de la unidad económica campesina. Buenos Aires, Argentina: Ediciones Nueva Visión.

Comité de Planeación para el Desarrollo (Coplade) (1996). Plan Estatal de Desarrollo 19952000: Chiapas. Segunda edición. México: Gobierno del estado de Chiapas.

Comisión Nacional para el Conocimiento y Uso de la Biodiversidad (CONABIO) (2018). División política municipal. Catálogo de metadatos geográficos. [en línea]. Disponible en: http://www. conabio.gob.mx/informacion/metadata/gis/muni 2018gw.xml? httpcache $\% 20=\% 20$ yes\& $\mathrm{xsl}=/ \mathrm{db} / \mathrm{metadata} / \mathrm{xsl} / \mathrm{fgdc}$ html.xsl\& indent $\% 20=\% 20$ no (Consultado el 5 de septiembre de 2019).

EntreDiversidades. Revista de Ciencias Sociales y Humanidades, vol. 8, núm. 1 (16), enero-junio 2021. Páginas: 92 - 118 ISSN-e: 2007-7610. https://doi.org/10.31644/ED.V8.N1.2021.A04 
Cuarto Poder (2018). "Inaugura MVC planta extractora de aceite de palma africana”. Cuarto Poder, [en línea]. Disponible en: https:/www.cuartopoder.mx/chiapas/inaugura-mvc-plantaextractora-de-aceite-de-palma-africana/183994/ (Consultado el 28 de diciembre de 2018).

Echánove, Flavia (2017). "La financiarización de la agricultura: la participación del plan de pensiones de Canadá en Glencore”. Papeles de Geografía, 63 (63), pp. 133-145. Disponible en: https://revistas.um.es/geografia/article/view/289201 (Consultado en agosto de 2020).

Fenner, Justus (2010). "Los deslindes en el porfiriato y la estructura agraria posrevolucionaria en Chiapas. Construcción y deconstrucción de un mito", en Fenner, Justus y Lisbona, Miguel (Coords). La Revolución mexicana en Chiapas: un siglo después: nuevos aportes, 19101940. México: Universidad Nacional Autónoma de México.

Fletes, Héctor y Bonanno, Alessandro (2015). "Respuestas a la crisis de la globalización neoliberal: intervención del Estado en la producción de aceite de palma en Chiapas, México”. Carta Económica Regional, año 27, núm. 116, pp. 5-35. También disponible en: http://www. cartaeconomicaregional.cucea.udg.mx/index.php/CER/article/view/6139/5646

Fletes, Héctor, et al. (2013). "Pequeños productores, reestructuración y expansión de la palma africana en Chiapas”. Región y Sociedad, 25 (57), pp. 203-239. También disponible en: $\underline{\text { http:// }}$ www.scielo.org.mx/scielo.php?script=sci arttext\&pid=S1870-39252013000200007

Gobierno del estado de Chiapas (2003). Tercer Informe de Gobierno. (Anexo 1, gráfico-estadístico). Tuxtla Gutiérrez, Chiapas: Talleres Gráficos.

Gobierno del estado de Chiapas (2004). Cuarto Informe de Gobierno. Tuxtla Gutiérrez, Chiapas: Talleres Gráficos.

Gobierno del estado de Chiapas (2012). Sexto Informe de gobierno (Anexo 1, indicadores del Plan de Desarrollo Chiapas Solidario 2007-2012). Tuxtla Gutiérrez, Chiapas: Gobierno del Estado de Chiapas.

Gobierno del estado de Chiapas (2016). Cuarto Informe de gobierno (región X, Soconusco). Tuxtla Gutiérrez, Chiapas: Talleres Gráficos.

Gobierno del estado de Chiapas (2019). Plan Estatal de Desarrollo 2019-2024. [en línea]. Chiapas, México: Gobierno del estado de Chiapas. Disponible en: http://www.haciendachiapas.gob. $\mathrm{mx} /$ planeacion/Informacion/PED/PED-2019.pdf (Consultado el 22 de diciembre de 2019).

Gómez, Ezequiel (2019). "Florece producción de palma de aceite en Chiapas", en Cuarto Poder, [en línea]. Disponible en: https:/www.cuartopoder.mx/chiapas/florece-produccion-depalma-de-aceite-en-chiapas/244958 (Consultado el 10 de noviembre de 2019).

Grupo Oleopalma (2019). ¿Quiénes somos? [en línea]. Grupo Oleomex. Disponible en: https:// oleopalma.com.mx/grupo-oleopalma-2/ (Consultado el 22 de noviembre de 2019).

Grupo Propalma (2019). Historia. [en línea]. Promotora de Palma del Soconusco SAPI de CV. Disponible en: http://www.propalma.com.mx/historia.html (Consultado el 25 de noviembre de 2019).

EntreDiversidades. Revista de Ciencias Sociales y Humanidades, vol. 8, núm. 1 (16), enero-junio 2021. Páginas: 92 - 118 ISSN-e: 2007-7610. https://doi.org/10.31644/ED.V8.N1.2021.A04 

campesina a partir de la adopción de la palma...

Gudynas, Eduardo (2009). "Diez tesis urgentes sobre el nuevo extractivismo. Contexto y demandas bajo el progresismo sudamericano actual”, en Schuldt, Jürgen, et al. (eds.). Extractivismo, politica y sociedad. Quito, Ecuador: Centro Andino de Acción Popular, Centro Latinoamericano de Ecología Social, pp. 187-225.

Gudynas, Eduardo (2012). "Estado compensador y nuevos extractivismos. Las ambivalencias del progresismo sudamericano”. Nueva Sociedad, núm. 237, pp. 128-146. También disponible en: https://nuso.org/articulo/estado-compensador-y-nuevos-extractivismoslas-ambivalencias-del-progresismo-sudamericano/

Guillén, Arturo (2000). México hacia el siglo XXI. Crisis y modelo económico alternativo. México: Universidad Autónoma Metropolitana, Plaza y Valdéz.

Holloway, John (1992). "La reforma del estado: capital global y Estado nacional". Perfiles Latinoamericanos, 1 (1), pp. 7-32. Disponible en: https://perfilesla.flacso.edu.mx/index. php/perfilesla/article/view/492 (Consultado en enero y octubre de 2020).

Instituto Nacional de Estadística y Geografía (INEGI) (2009). Censo Agropecuario (2007). VIII Censo Agricola, Ganadero y Forestal. [en línea] Aguascalientes, México: Instituto Nacional de Estadística y Geografía. Disponible en: https://www.inegi.org.mx/programas/ cagf/2007/ (Consultado en noviembre y diciembre de 2019).

Instituto Nacional de Estadística y Geografía (INEGI) (2016). Actualización del Marco Censal Agropecuario (2016). [en línea]. Disponible en https://www.inegi.org.mx/programas/ amca/2016/default.html\#Tabulados (Consultado en abril y diciembre de 2019).

Kay, Cristobal (2016). "La transformación neoliberal del mundo rural: procesos de concentración de la tierra y del capital y la intensificación de la precariedad del trabajo". Revista Latinoamericana de Estudios Rurales, 1 (1), pp.1-26. También disponible en: http://www.ceil-conicet.gov.ar/ojs/index.php/revistaalasru/article/view/93

Lander, Eduardo (2014). El neoextractivismo como modelo de desarrollo en América Latina y sus contradicciones. Berlín, Alemania: Fundación Heinrich Böll.

Marx, Karl (1999 [1867]). El capital I, crítica de la economía política. México: Fondo de Cultura Económica.

Mazariegos, Adriana, et al. (2014). "La industria de la palma de aceite en Acapetahua, Chiapas: el caso de Propalma”. Revista Mexicana de Agronegocios, vol. 35, pp. 1052-1064. También disponible en: https://www.redalyc.org/pdf/141/14131676014.pdf

McMichael, Philip (2015). Regímenes agroalimentarios y cuestiones agrarias. México: Universidad Autónoma de Zacatecas.

Ortiz, Arturo (2001 [1989]). Politica económica de México 1982-2000. El fracaso neoliberal. México: Editorial Nuestro Tiempo.

Pareyón, Rebeca (2015). "El sector primario exportador como base para la industrialización en América Latina durante los siglos XIX y XX”. Tiempo Económico, 10 (29), pp. 21-31. También disponible en: http://tiempoeconomico.azc.uam.mx/wp-content/ uploads/2017/08/29te2.pdf

EntreDiversidades. Revista de Ciencias Sociales y Humanidades, vol. 8, núm. 1 (16), enero-junio 2021. Páginas: 92 - 118 ISSN-e: 2007-7610. https://doi.org/10.31644/ED.V8.N1.2021.A04 
París, María Dolores (2006). "Sindicalismo agrario e indigenismo laboral en el Soconusco, Chiapas: 1934-1940". Secuencia, núm. 65, pp. 69-90. También disponible en: https:// doi.org/10.18234/secuencia.v0i65.969

Peña, Eulalia y Romero, Emilio (Coords.) (1995). La modernización del campo y la globalización económica. México: Instituto de Investigaciones Económicas, Universidad Nacional Autónoma de México.

Pérez, Eliezer Fernando (2011). La transición del campesinado al sistema asalariado en el modelo neoliberal. Caso: Soconusco, Chiapas. 1982-2009. Tesis para obtener el grado de Licenciatura en Economía. Facultad de Ciencias Sociales, Universidad Autónoma de Chiapas.

Pichardo, Beatriz (2006). "La revolución verde en México”. AGRÁRIA (Sáo Paulo. Online), núm. 4, pp. 40-68. Disponible en: https://doi.org/10.11606/issn.1808-1150.v0i4p40-68 (Consultado en agosto de 2020).

Proyecto Mesoamérica (2013). Programa Mesoamericano de Biocombustibles (PMB). Hojas Informativas, actualización al 31 de noviembre de 2014. [en línea]. Disponible en: http://www.proyectomesoamerica.org/ (Consultado el 12 de agosto de 2019).

Ramírez, Camilo Alexander (2011). Aproximación a la relación entre el proceso de financiarización de la economía y el cultivo de palma africana en Colombia. Monografía para optar el título profesional de Administrador de Empresas, Facultad de Ciencias Económicas, Universidad Nacional de Colombia.

Renard, Marie Christine (1993). El Soconusco: una economía cafetalera. México: Universidad Autónoma Chapingo.

Reyes, María (1992). El reparto de tierra y la politica agraria en Chiapas. 1914 1988. México: Universidad Nacional Autónoma de México. Centro de Investigaciones Humanísticas de Mesoamérica y del estado de Chiapas.

Román, Carolina (2015). Ganadería bovina ejidal, en el municipio de Mapastepec, Chiapas. En el marco del modelo económico neoliberal 1990-2014. Tesis para obtener el grado de Maestría en Ciencias en Desarrollo Rural Regional, Universidad Autónoma Chapingo.

Rubio, Blanca (2003). Explotados y excluidos. Los campesinos latinoamericanos en la fase agroexportadora neoliberal. México: Plaza y Valdés Editores.

Rubio, Blanca (2018). "La agricultura latinoamericana en la transición mundial: una visión histórica estructural, 2003-2016”, en Rubio, Blanca (Coord.). América Latina en la mirada. Las transformaciones rurales en la transición capitalista. México: Universidad Nacional Autónoma de México, pp. 21-62.

Rubio, Blanca (Coord.) (2013). La crisis alimentaria mundial. Impacto sobre el campo mexicano. México: Instituto de Investigaciones Sociales, Universidad Nacional Autónoma de México. Miguel Ángel Porrúa.

Rubio, Blanca (2019). "La dependencia alimentaria en tiempos de desvalorización de las materias primas: México en la encrucijada”, en Rubio, Blanca y Pasquier, Ayari (Coords). Inseguridad alimentaria y politicas de alivio a la pobreza. Una visión multidisciplinaria. México: Universidad Nacional Autónoma de México, pp. 17-38.

EntreDiversidades. Revista de Ciencias Sociales y Humanidades, vol. 8, núm. 1 (16), enero-junio 2021. Páginas: 92 - 118 ISSN-e: 2007-7610. https://doi.org/10.31644/ED.V8.N1.2021.A04 
Rubio, Blanca y Moguel, Julio (2018). "La agricultura mexicana en la encrucijada: un futuro incierto”, en Rubio, Blanca (Coord.). América Latina en la mirada. Las transformaciones rurales en la transición capitalista. México: Universidad Nacional Autónoma de México, pp. 63-92.

Santacruz, Eugenio y Palacio, Víctor (2018). "Las políticas públicas para el cultivo de palma de aceite. El caso de la región Soconusco, Chiapas, México”. Revista de Geografía Agrícola, núm 60, pp. 81-103. También disponible en: https://chapingo-cori.mx/geografia/geografia/ article/view/r.rga.2018.60.003

Schejtman, Alexander (1980). "Economía campesina: lógica interna, articulación y persistencia”. Revista de la CEPAL, núm. 11, pp. 121-140. Disponible en: https://repositorio.cepal. org/handle/11362/11934 (Consultado el 20 de noviembre de 2019).

Servicio de Información Agroalimentaria y Pesquera (SIAP) (2018). Cultivo de palma africana $o$ aceitera. Producción agrícola, perenne, modalidad riego más temporal. [en línea]. Disponible en: https://nube.siap.gob.mx/cierreagricola/ (Consultado el 4 de noviembre de 2019).

Servicio de Información Agroalimentaria y Pesquera (SIAP) (2019). Anuario Estadístico de la Producción Agrícola. [en línea] México: Gobierno de México. Disponible en: https://nube.siap.gob.mx/cierreagricola/ (Consultado del 11 al 14 de diciembre de 2019).

Shanin, Teodor (1983). La clase incómoda. Sociología politica del campesinado en una sociedad en desarrollo (Rusia 1910-1925). Espańa: Alianza Editorial.

Svampa, Maristella (2017). Del cambio de época al fin de ciclo. Buenos Aires, Argentina: Edhasa.

Teubal, Miguel y Palmisano, Tomás (2015). “¿Hacia la reprimarización de la economía? En torno al modelo extractivo en la posconvertibilidad”. Realidad económica, núm. 296, pp. 55-75. También disponible en: https://ri.conicet.gov.ar/handle/11336/72628

Tovar, María Elena (2006). Los finqueros extranjeros en el Soconusco durante el Porfiriato. México: Universidad de Ciencias y Artes de Chiapas, Consejo de Ciencia y Tecnología de Chiapas.

Trejo, Enrique, Guillermo Valdiviezo y Héctor Fletes (2018). "Reestructuración productiva: el caso de la palma de aceite en la microrregión costera de Chiapas”, en Fletes, Héctor, Vargas, Perla y Jiménez, Hilda (Eds.). Actores, reconfiguración socioterritorial y desarrollo en Chiapas. México: Universidad Autónoma de Chiapas, pp. 77-105.

Villafuerte, Daniel (1992). Desarrollo económico y diferenciación productiva en el Soconusco. México: Centro de Investigaciones Ecológicas del Sureste, Unidad de Estudios Económicos y Sociales.

Villafuerte, Daniel y García, María del Carmen (2014). "Tres ciclos migratorios en Chiapas: interno, regional e internacional”. Migración y Desarrollo, 12 (22), pp. 3-37. También disponible en: http://www.scielo.org.mx/scielo.php?script=sci arttext\&pid=S1870-75992014000100001

Wallerstein, Immanuel (2005). La crisis estructural del capitalismo. San Cristóbal de Las Casas, Chiapas, México: Centro Indígena de Capacitación Integral A. C. Unitierra Chiapas. Contrahistorias, La otra mirada de Clío.

EntreDiversidades. Revista de Ciencias Sociales y Humanidades, vol. 8, núm. 1 (16), enero-junio 2021. Páginas: 92 - 118 ISSN-e: 2007-7610. https://doi.org/10.31644/ED.V8.N1.2021.A04 